\title{
Differences in the Mechanisms of Cell-Cell and Cell-Substrate Adhesion Revealed in a Human Retinoblastoma Cell Line
}

\author{
Kenji Uéda, Masatoshi Takeichi and T. S. Okada \\ Department of Biophysics, Faculty of Science, University of Kyoto, Kyoto 606, \\ Japan
}

\begin{abstract}
Cellular adhesive properties of Y79 cells established from a human retinoblastoma were investigated. Y79 cells were characterized by their mutual adhesiveness in forming clusters and by the complete inability to attach to a non-cellular culture substrate. The cell-cell adhesion of Y79 cells depends on two different mechanisms. One is $\mathrm{Ca}^{2+}$-dependent and the other $\mathrm{Ca}^{2+}$ independent, as in the case of V79 cells which adhere mutually and to the culture substrate. That Y79 cells share common adhesive sites for cell-cell adhesion with V79 cells was suggested from the results of the heterotypic aggregation of these two cell types. Y79 cells attached themselves to a monolayer of V79 cells, but not to the substrate of the plastic dishes, when the medium contained serum. We concluded that the mechanisms that operate for cell-substrate adhesion differs qualitatively from the mechanisms for cell-cell adhesion.
\end{abstract}

Most animal cells cultured in vitro grow by attaching themselves to the culture substrate as well as to neighbouring cells. Our recent studies using V79 cells, a typical fibroblastic cell line derived from Chinese hamster lungs (13), have shown that their mutual adhesion is due to two different mechanisms, a $\mathrm{Ca}^{2+}$-dependent and a $\mathrm{Ca}^{2+}$ independent mechanism $(9,10)$. We can obtain cells with either of these cell-cell adhesion mechanisms by dispersing the cells with different treatments.

Some other cell lines grow in suspension, without attaching themselves to the culture substrate, although they adhere mutually to form clusters. Cells of line Y79, derived from a human retinoblastoma (7), are typical of this adhesive property. Thus, we wished to compare the mechanisms operating for the adhesion of Y79 cells with those for V79 cells. Since Y79 cells lack the ability for cell-substrate adhesion, this comparison will hopefully help to solve the problem as to whether the mechanisms for cell-substrate adhesion differs qualitatively from those for the cell-cell adhesion.

\footnotetext{
Abbreviations: MEM, Eagle's minimum essential medium; FCS, fetal calf serum; $\mathrm{CMF}, \mathrm{Ca}^{2+}$ - and $\mathrm{Mg}^{2+}$-free Puck's saline; HEPES, $N$-2-hydroxyethylpiperazine- $N^{\prime}$-2-ethanesulfonic acid; HCMF, CMF buffered with $10 \mathrm{mM}$ HEPES; FITC, fluorescein isothiocyanate; TC-V79 and-Y79, V79 and Y79 cells dispersed with trypsin $(0.01 \%)$ with $\mathrm{Ca}^{2+}$; TE-V79 and $-\mathrm{Y} 79, \mathrm{~V} 79$ and $\mathrm{Y} 79$ cells dispersed with trypsin $(0.01 \%)$ with EDTA; LTE-V79 and -Y79, V79 and Y79 cells dispersed with the lower concentrations of trypsin (0.0001-0.0005\%) with EDTA.
} 


\section{MATERIALS AND METHODS}

Cells. Cells of the Chinese hamster line V79 (13) were grown as described previously (9). The human retinoblastoma cell line Y79 (7), which was supplied by Dr. Russell, of the National Eye Institute, NIH, was maintained in suspension culture with Eagle's minimum essential medium (MEM) with double the concentration of amino acids and vitamins and a supplement of $6 \%$ fetal calf serum (FCS, Flow Laboratories).

Cell dispersion. Monolayers of V79 cells were dispersed into single cells as described previously (11). Cells with the $\mathrm{Ca}^{2+}$-independent adhesion mechanism were obtained by treating the monolayers with $0.0001 \%$ crystallized trypsin (type I, Sigma Chemical Co.) and $1 \mathrm{mM}$ EDTA in $\mathrm{Ca}^{2+}$ - and $\mathrm{Mg}^{2+}$-free Puck's saline (CMF) buffered with $10 \mathrm{mM}$ HEPES ( $N$-2-hydroxyethylpiperazine- $N$ '-2-ethanesulfonic acid) at pH 7.4 (HCMF) (9) (abbreviated to as LTE-V79). Cells with the $\mathrm{Ca}^{2+}$-dependent adhesion mechanism were obtained by treating the monolayers with $0.01 \%$ crystallized trypsin in $\mathrm{HCMF}$ with $0.2 \mathrm{mM} \mathrm{CaCl}_{2}$ (abbreviated to as TC-V79). To disperse the Y79 cells, cell clusters were pelleted and washed with CMF. If the medium for cell dispersion used in the following steps contained $\mathrm{CaCl}_{2}$, the cell clusters were washed with CMF supplemented with $1 \mathrm{mM} \mathrm{CaCl}$. Washed cells were suspended and treated in the dispersion media (described in results) at $37^{\circ} \mathrm{C}$ for $15 \mathrm{~min}$ in a reciprocal shaker. After washing them three times with chilled CMF, the dispersed cells were resuspended in HCMF.

Aggregation of V79 and $Y 79$ cells. A suspension of $2 \times 10^{5}$ cells in $0.5 \mathrm{ml} \mathrm{HCMF}$ with or without $1 \mathrm{mM} \mathrm{CaCl} 2$ was placed in a plastic well (cat. no. 76-033-05, Linbro Scientific) and incubated at $37^{\circ} \mathrm{C}$ on a gyratory shaker at $80 \mathrm{rpm}$. The degree of cell aggregation was taken as the ratio of the total particle number at the indicated incubation time $\left(\mathrm{N}_{\mathrm{t}}\right)$ to the total cell number $\left(\mathbf{N}_{\circ}\right)$. The total particle number in a given cell suspension was counted with a Coulter counter (model $Z_{B}$, Coulter Electronics Inc.) with a $100-\mu \mathrm{m}$ aperture. For details of the method, see the previous paper (9).

For the heterotypic aggregations, $1 \times 10^{5}$ cells of V79 and Y79, either of which were labeled with fluorescein isothiocyanate (FITC) as described previously (10), were mixed together in $0.5 \mathrm{ml} \mathrm{HCMF}$ and incubated as described above. The cell aggregates obtained were examined under a fluorescence microscope (model BH-RFL, Olympus).

\section{RESULTS}

Aggregation of Y79 cells. The aggregation of Y79 cells was examined after dispersing the cell clusters with various concentrations of trypsin, ranging from 0 to $0.01 \%$, in the presence of $1 \mathrm{mM}$ EDTA. As the cells dispersed at the higher concentrations of trypsin, they became less aggregative (Table 1). The addition of $\mathrm{Ca}^{2+}$ hardly promoted the aggregation of these cells. Cells treated with $0.01 \%$ trypsin (abbreviated TE-Y79) lost most of their aggregability. It was sometimes difficult to dissociate the cell clusters completely into single cells with a concentration of trypsin lower than 0.0002 $\%$. Figure 1-a shows a typical kinetic pattern for the aggregation of Y79 cells dispersed with $0.0005 \%$ trypsin and $1 \mathrm{mM}$ EDTA (abbreviated LTE-Y79) in the absence or presence of $\mathrm{Ca}^{2+}$.

The aggregation of Y79 cells dispersed with $0.01 \%$ trypsin containing various concentrations $(0-0.5 \mathrm{mM})$ of $\mathrm{CaCl}_{2}$ is shown in Table 2 . Cells dispersed with $0.01 \%$ trypsin containing $0.1-0.5 \mathrm{mM} \mathrm{Ca}{ }^{2+}$ aggregated strongly when $\mathrm{Ca}^{2+}$ was present in the assay medium but hardly aggregated in its absence. A typical kinetic pattern for 
TABLE 1. AgGREGATION OF Y79 CELLS AFTER TREATMENT WITH DIFFERENT CONCENTRATIONS OF TRYPSIN

\begin{tabular}{ccc}
\hline \multirow{2}{*}{ Concentration of trypsin $(\%)^{a}$} & \multicolumn{2}{c}{ Aggregation $\left(\mathrm{N}_{60} / \mathrm{N}_{0}\right)^{b}$} \\
\cline { 2 - 3 } & with $\mathrm{Ca}^{2+}$ & without $\mathrm{Ca}^{2+}$ \\
0.0001 & 0.332 & 0.308 \\
0.0002 & 0.320 & 0.247 \\
0.0005 & 0.289 & 0.198 \\
0.001 & 0.285 & 0.237 \\
0.01 & 0.426 & 0.428 \\
\end{tabular}

a Trypsin was dissolved in HCMF containing $1 \mathrm{mM}$ EDTA. Cells were dissociated by incubating the cell clusters for $15 \mathrm{~min}$ at $37^{\circ} \mathrm{C}$ in trypsin.

${ }^{b}$ Aggregation was measured after incubation for $60 \mathrm{~min}$ at $37^{\circ} \mathrm{C}$. Each value is the mean of triplicate cultures.

the aggregation of Y79 cells dispersed with $0.01 \%$ trypsin containing $0.1 \mathrm{mM} \mathrm{Ca}^{2+}$ (abbreviated TC-Y79) is shown in Fig. 1b.

When LTE-Y79 and TC-Y79 cells were mixed after labeling either of them with FITC, they aggregated independently (Fig. 2). This is evidence that LTE-Y79 and TC-Y79 cells have different mechanisms for cell-cell adhesion, as reported in comparable experiments using V79 cells (10). Perhaps, TC-Y79 cells have only the $\mathrm{Ca}^{2+}$ dependent mechanism, and LTE-Y79 cells only the $\mathrm{Ca}^{2+}$-independent mechanism.

Adhesion of Y79 cells to the V79 cell monolayer. Usually Y79 cells do not attach themselves to the culture dish (Fig. 3a). To examine whether they can attach themselves to the top of a monolayer of V79 cells, we inoculated TE-Y79 cells $\left(1 \times 10^{6}\right)$ suspended in MEM with $6 \%$ FCS on a monolayer of V79 cells in the semi-confluent

(a) LTE - Y79

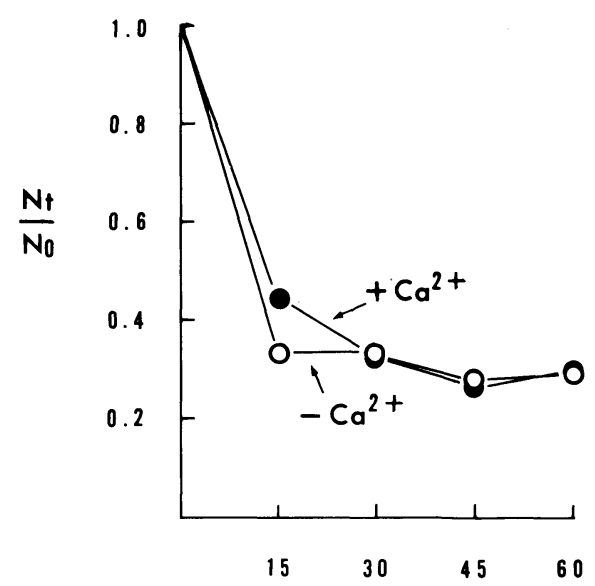

(b) TC-Y79

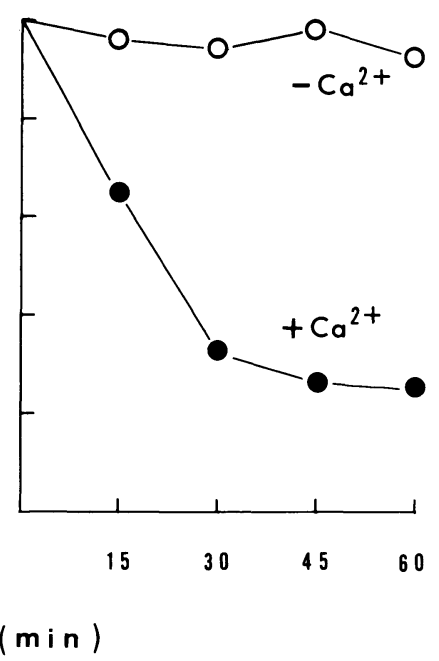

Fig. 1. Typical kinetic patterns of the aggregations of Y79 cells (a) dispersed with $0.0005 \%$ trypsin with $1 \mathrm{mM}$ EDTA (LTE-Y79) and (b) dispersed with $0.01 \%$ trypsin containing $0.1 \mathrm{mM} \mathrm{Ca}^{2+}$ (TC-Y79). Each point represents the average value of three determinations. 
TABLE 2. AgGREGATION OF Y79 CELLS AFTER TREATMENT WITH TRYPSIN CONTAINING VARIOUS CONCENTRATIONS OF $\mathrm{Ca}^{2+}$

\begin{tabular}{ccc}
\hline \multirow{2}{*}{ Concentration of $\mathrm{Ca}^{2+}(\mathrm{mM})^{a}$} & \multicolumn{2}{c}{ Aggregation $\left(\mathrm{N}_{60} / \mathrm{N}_{0}\right)^{b}$} \\
\cline { 2 - 3 } & with $\mathrm{Ca}^{2+}$ & without $\mathrm{Ca}^{2+}$ \\
\hline 0 & 0.820 & 0.748 \\
0.1 & 0.197 & 0.780 \\
0.2 & 0.177 & 0.800 \\
\end{tabular}

$\mathrm{CaCl}_{2}$ was added to $0.01 \%$ trypsin in $\mathrm{HCMF}$.

${ }^{b}$ Aggregation was measured after incubation for $60 \mathrm{~min}$ at $37^{\circ} \mathrm{C}$. Each value is the mean of triplicate cultures.
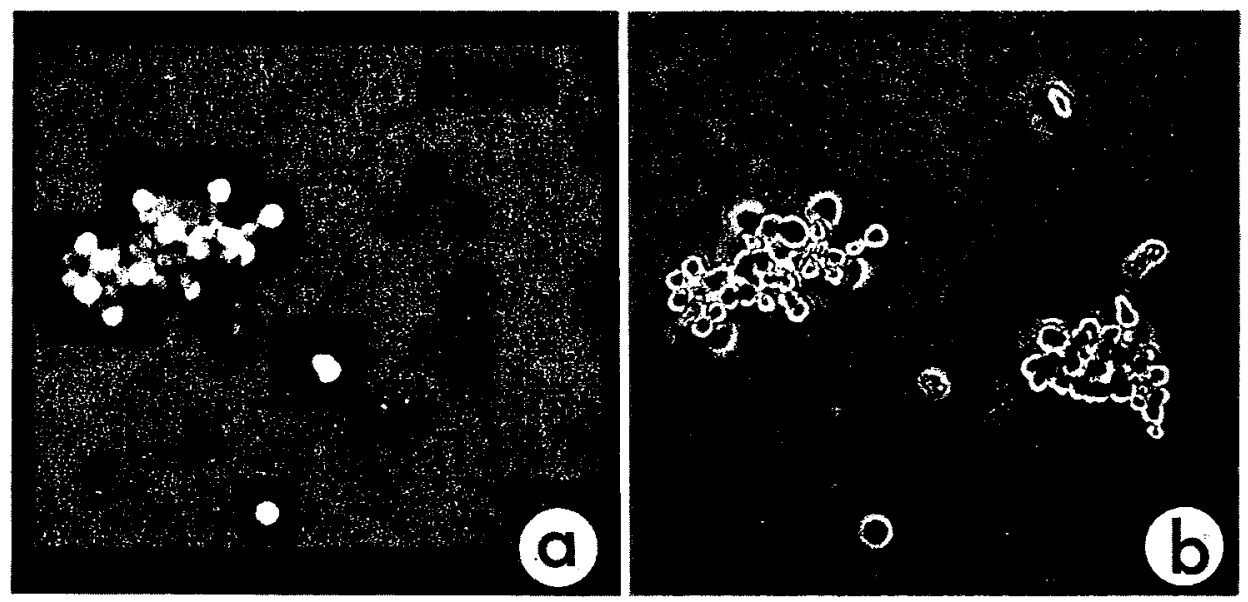

Fig. 2. Segregation of aggregates of Y79 cells with different adhesion sites. LTE-Y79 cells labeled with FITC were mixed with TC-Y79 cells and incubated for $30 \mathrm{~min}$ at $37^{\circ} \mathrm{C}$. (a) fluorescent photomicrograph; (b) phase-contrast photomicrograph of the same field as (a). Magnification, $\times 240$.

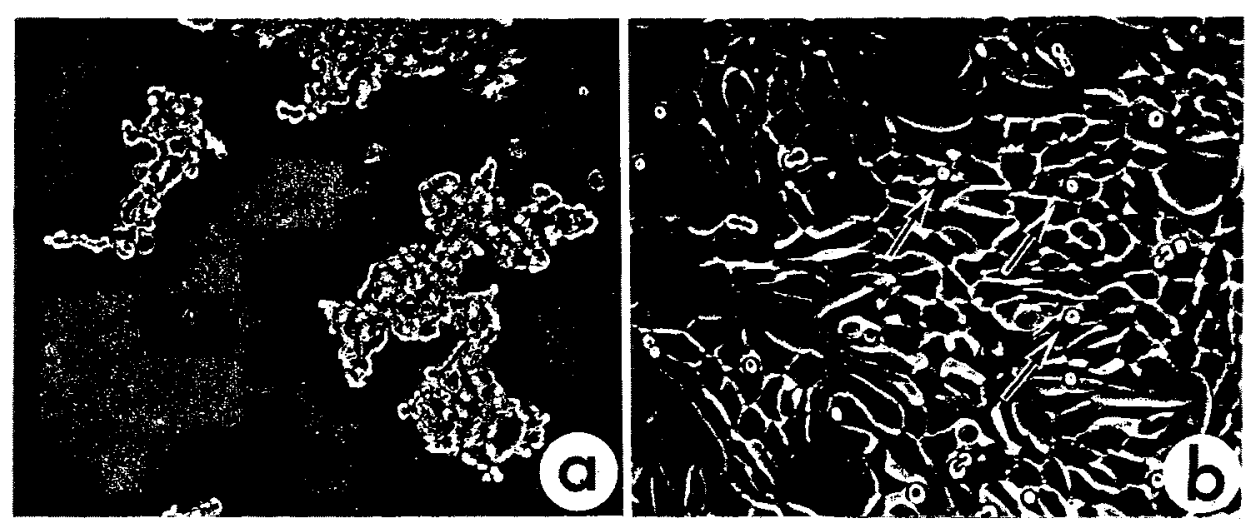

Fig. 3. Photomicrographs of (a) Y79 cells in suspension culture and (b) Y79 cells attached to V79 cells. Y79 cells were incubated for $9 \mathrm{~h}$ after their inoculation onto a V79 cell monolayer. Arrows indicate Y79 cells. Magnification, $\times 125$. 
TABLE 3. AdHESION OF Y79 Cells to the CULTURE SUBSTRATE AND to A MONOLAYER OF V79 CELLS

\begin{tabular}{|c|c|c|}
\hline \multirow{2}{*}{ Experiment $^{a}$} & \multicolumn{2}{|c|}{ Number of Unattached Cells $\left(\times 10^{-2}\right)^{b}$} \\
\hline & $9 \mathrm{~h}$ & $24 \mathrm{~h}$ \\
\hline On a Falcon culture dish & 8,800 & 9,500 \\
\hline On a V79 monolayer ${ }^{c}$ & 3.3 & 0.63 \\
\hline
\end{tabular}

a Y79 cells $\left(1 \times 10^{6}\right)$ were inoculated with $5 \mathrm{ml}$ of MEM supplemented with $6 \%$ FCS in a fresh Falcon plastic culture dish or on a monolayer of V79 cells which had been inoculated in the culture dishes the preceding day. Cultures were incubated for the indicated periods at $37^{\circ} \mathrm{C}$.

$b$ Mean values obtained from 4 plates.

$c$ The number of spontaneously detached V79 cells were counted by incubating the V79 cell monolayers without Y79 cells for the indicated times. This value was subtracted from the total number of unattached cells in the incubation of Y79 cells on V79 cell monolayers to obtain the true values for unattached Y79 cell numbers.

state in a Falcon plastic dish with a diameter of $6 \mathrm{~cm}$ (about $7 \times 10^{4}$ cells $/ \mathrm{cm}^{2}$ ). After incubation for $9 \mathrm{~h}$ at $37^{\circ} \mathrm{C}$, the number of unattached cells was counted (Table 3). In the control experiment in which TE-Y79 cells were inoculated into dishes without V79 cells, cell attachment to the substrate was negligible during $24 \mathrm{~h}$. But more than $99 \%$ of the inoculated cells attached themselves to a V79 cell monolayer within $9 \mathrm{~h}$, and the attached Y79 cells remained round (Fig. 3b). In the medium without serum, all the TE-Y79 cells inoculated attached themselves to the culture dish quickly, although they came off after several hours of incubation.

The adhesion of TC-Y79 and LTE-Y79 cells to a monolayer of V79 cells and to the culture substrate was similar to that of TE-Y79 cells, except that these cells adhere more quickly to the V79 monolayer than did TE-cells.

Heterotypic aggregation of V79 and Y79 cells. To test whether Y79 and V79 cells have common adhesion sites for their mutual adhesion, we mixed these two types of cells after various dispersion treatments and allowed them to aggregate in HCMF with $1 \mathrm{mM} \mathrm{Ca}^{2+}$. Cells of different types were distinguished by labeling either of the two cell populations with FITC.

V79 and Y79 cells aggregated independently in such combinations that one cell type had only the $\mathrm{Ca}^{2+}$-dependent adhesion mechanism, and the other only the $\mathrm{Ca}^{2+}$ independent adhesion mechanism; i.e., a combination of either LTE-V79 and TC-Y79 or TC-V79 and LTE-Y79 (Figs. $4 \mathrm{a}$ and $4 \mathrm{~b}$ ).

When TC-V79 and TC-Y79 cells combined, they mixed randomly in the aggregates (Figs. 4c and 4d). LTE-V79 and LTE-Y79 also formed aggregates in which both cell types were present. In this combination, however, cells of one type tended to separate from cells of the other within an aggregate (Figs. $4 \mathrm{e}$ and $4 \mathrm{f}$ ).

In the medium without $\mathrm{Ca}^{2+}$, TC-Y79 and TC-V79 cells remained dispersed in all the above heterotypic cell combinations; they did not adhere to LTE-V79 or LTE-Y79 cells. The pattern of aggregation for LTE-V79 and LTE-Y79 cells in their mixture was not altered in this medium.

\section{DISCUSSION}

Y79 cells were established from a human retinoblastoma, a tumor originating in the neural retina of a child's eye. Several cytological properties of these cells have 


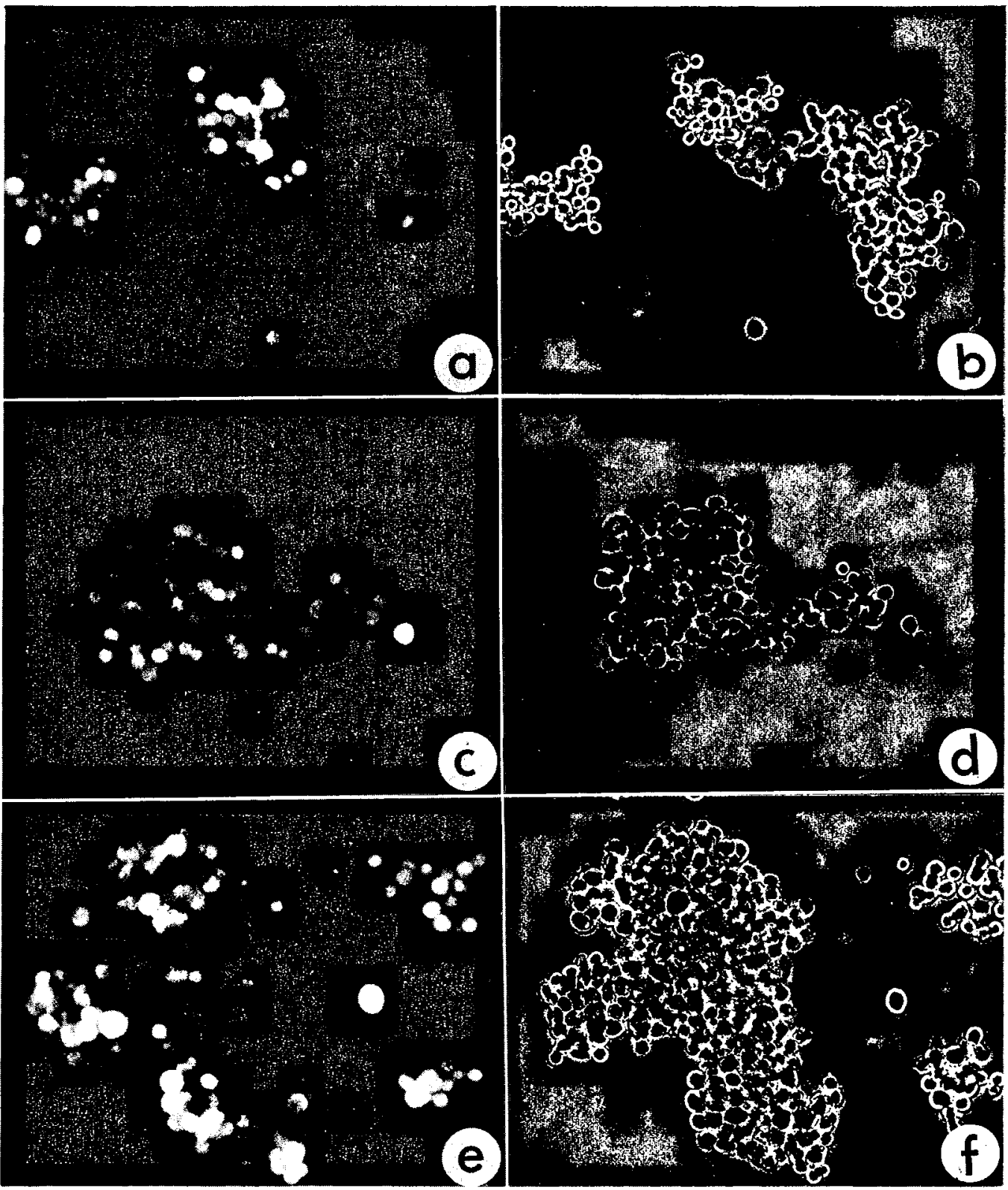

Fig. 4. Heterotypic aggregation of V79 and Y79 cells. (a) and (b), LTE-V79+TC-Y79; (c) and (d), TC-V79+TC-Y79; (e) and (f), LTE-V79+LTE-Y79. (a), (c) and (e) are fluorescent photomicrographs. (b), (d) and (f) are phase-contrast photomicrographs of the same field as (a), (c) and (e), respectively. In all cases, V79 cells were labeled with FITC. Cells were aggregated for $30 \mathrm{~min}$ at $37^{\circ} \mathrm{C}$. Magnification, $\times 200$. 
been studied $(1,5,6,7)$. We have been interested particularly in the adhesive properties of these cells, since they mutually adhere to form clusters, but never attach themselves to the culture substrate. Our present results show that Y79 cells have two mechanisms for aggregation, a $\mathrm{Ca}^{2+}$-dependent and a $\mathrm{Ca}^{2+}$-independent mechanism. In this respect, the adhesive properties of these cells are similar to those of V79 cells (11). When Y79 and V79 cells (which had been dispersed in such a way that they retained either the $\mathrm{Ca}^{2+}$-dependent or the $\mathrm{Ca}^{2+}$-independent adhesion mechanism) were mixed, they formed chimeric aggregates. Partial segregation of Y79 and V79 cells in the chimeric aggregates formed by the $\mathrm{Ca}^{2+}$-independent mechanism suggest that the molecules involved in this type of cell-cell adhesion mechanism have some cell type-specificity. A similar phenomenon was observed in the heterotypic aggregation of V79 and embryonic neuro-retinal cells (10). With the $\mathrm{Ca}^{2+}$-dependent mechanism, Y79 and V79 cells were connected nonspecifically as in the combination of V79 and neuro-retinal cells (10).

Y79 cells thus are considered to have cell-cell adhesion sites which are common in V79 cells. This is evidence that the characteristic property of Y79 cells not to adhere to a non-cellular substrate is due to the lack of the some cell surface molecules essential for cell-substrate adhesion. Naturally, these molecules must differ from those required for cell-cell adhesion. Y79 cells adhere tightly to the culture dish if the medium does not contain serum, as observed in the cell-substrate adhesion of other cells $(2,8)$. In the presence of serum, some serum proteins may be quickly adsorbed on the surface of the culture substrate, and cells then will settle on the serum-coated substrate. Cells which are adhesive to the culture substrate may have receptor molecules on their surface that combine with adsorbed serum proteins (2). Such receptors may be lacking in Y79 cells.

We can assume that there is another factor which reduces the adhesiveness of cells to the culture substrate, the inability of cells to spread on the substrate. Cells establish multiple contact points between the cell surface and the substrate by actively spreading over the latter $(3,12)$. If cells cannot spread, they may not be able to make enough contact points to stabilize themselves on the substrate. When Y79 cells adhered to the culture dish in the serum-free medium or to the monolayer of V79 cells, they kept their round morphology, evidence of their inability to spread. We do not know yet what cellular properties are directly related to the low adhesiveness of Y79 cells on the non-cellular substrate.

In many in vitro cultures, neuronal cells do not attach directly to the culture dish unless the latter previously has been coated with collagen or polycations such as polylysine, but they do adhere to the top of a layer of glial cells (4). Y79 cells, derived from a neural retinal cell tumor, probably retain adhesive characteristics that are more or less specific to neuronal cells. The study of the adhesion of Y79 cells to other cells or to substrates may provide a model with which to determine the mechanism of interactions between neuronal cells and non-neuronal cells in situ.

Acknowledgments. We are grateful to Dr. P. Russell, of the National Eye Institute, NIH, for the supply of Y79 cells. We thank Miss Y. Katsurayama for helping us in the preparation of the manuscript. This study was supported by a Research Grant for Basic Cancer Research from the Ministry of Education, Science and Culture, Japan and by a Research Fund from Yamada Science Foundation. 


\section{REFERENCES}

1. Craft, J. L., N. L. Robinson, N. A. Roth and D. M. Albert. Scanning electron microscopy of retinoblastoma. Exp. Eye Res. 27, 519-531, 1978

2. Grinnel, F. Cellular adhesiveness and extracellular substrata. Int. Rev. Cytol. 53, 65-144, 1978

3. Harris, A. Location of cellular adhesions to solid substrata. Develop. Biol. 35, 97-114, 1973

4. Letourneau, P. C. Possible roles for cell-to-substratum adhesion in neuronal morphogenesis. Develop. Biol. 44, 77-91, 1975

5. McFal.t, R. C., T. W. Sery and M. Makadon. Characterization of a new continuous cell line derived from a human retinoblastoma. Cancer Res. 37, 1003-1010, 1977

6. McFall, R. C., R. M. Nagy, B. T. Nagle and L. M. McGreevy. Scanning electron microscopic observation of two retinoblastoma cell lines. Cancer Res. 38, 2827-2835, 1978

7. Reid, T. W., D. M. Albert, A. S. Rabson, P. Russell, J. Craft, E. W. Chu, T. S. Tralka and J. L. Wilcox. Characteristics of an established cell line of retinoblastoma. J. Natl. Cancer Inst. 53, 347-360, 1974

8. TAKEICHI, M. Changes in the properties of cell-substrate adhesion during cultivation of chicken fibroblasts in vitro in a serum-free medium. Exp. Cell Res. 72, 88-96, 1971

9. TAKEICHI, M. Functional correlation between cell adhesive properties and some cell surface proteins. J. Cell Biol. 75, 464-474, 1977

10. TaKeichi, M., H. S. OzaKi, K. Tokunaga and T. S. OKada. Experimental manipulation of cell surface to affect cellular recognition mechanisms. Develop. Biol. 70, 195-205, 1979

11. Urushihara, H., H. S. OzaKi and M. TAKeICHI. Immunological detection of cell surface components related with aggregation of Chinese hamster and chick embryonic cells. Develop. Biol. 70, 206-216, 1979

12. Wehland, J., M. Osborn and K. Weber. Cell-to-substratum contacts in living cells: A direct correlation between interference-reflexion and indirect-immunofluorescence microscopy using antibodies against actin and $a$-actinin. J. Cell Sci. 37, 257-273, 1979

13. YU, C. K. and W. K. SInclair. Homogeneity and stability of chromosomes of Chinese hamster cells in vitro. Can. J. Genet. Cytol. 6, 109-116, 1964

(Received for publication, May 23, 1980) 